\title{
Overexpression of Her-2 upregulates FoxM1 in gastric cancer
}

\author{
WEIWEI QI ${ }^{1}{ }^{*}$, XIAOXIAO LI ${ }^{*}$, YONGCHUN ZHANG ${ }^{1}$, RUYONG YAO $^{2}$, \\ WENSHENG QIU ${ }^{1}$, DONGFANG TANG ${ }^{3}$ and JUN LIANG ${ }^{1}$ \\ ${ }^{1}$ Department of Oncology, ${ }^{2}$ Central Laboratory and ${ }^{3}$ Department of Thoracic Surgery, \\ The Affiliated Hospital of Qingdao University Medical College, Qingdao, Shandong 266003, P.R. China
}

Received December 2, 2013; Accepted March 17, 2014

DOI: $10.3892 / \mathrm{ijmm} .2014 .1732$

\begin{abstract}
The transcription factor, forkhead box protein M1 (FoxM1), and the tyrosine kinase receptor, human epidermal growth factor receptor-2 (Her-2), are aberrantly expressed in a number of human malignancies, and are closely associated with the development of cancer. However, their regulatory mechanisms and their involvement in tumor development have not been extensively investigated, particularly in gastric cancer. In the present study, we examined the expression levels of FoxM1 and Her-2 in samples from patients with gastric cancer, as well as gastric cancer cell lines. Their regulatory mechanisms and the connection between them were also explored. We found that FoxM1 and Her-2 expression was markedly higher in the gastric cancer samples, while a strong association was found between them at the mRNA and protein level. When we regulated the levels of Her-2 in the gastric cancer cell lines, the expression of FoxM1 changed accordingly. Following the transfection of Her-2 expression vectors into the gastric cell lines, the luciferase activity of the FoxM1 promoter positively increased along with the concentration of pcDNA3.1-Her-2. However, Her-2-siRNA inverted this variation, which was further confirmed by treatment with the Her-2 inhibitor, trastuzumab, revealing that Her-2 regulates FoxM1 expression at the promoter level in gastric cancer cells. Our results suggest that FoxM1 and Her-2 are important diagnostic markers for gastric cancer. FoxM1 may be a potential cellular target for therapeutic intervention, particularly in gastric cancers resistant to Her-2targeted therapy.
\end{abstract}

\section{Introduction}

Forkhead box protein M1 (FoxM1) belongs to the forkhead transcription factor family, which shares the same

Correspondence to: Professor Jun Liang, Department of Oncology, The Affiliated Hospital of Qingdao University Medical College, 16 Jiangsu Road, Qingdao, Shandong 266003, P.R. China

E-mail: ljqyfy@163.com

*Contributed equally

Key words: forkhead box protein M1, human epidermal growth factor receptor-2, diagnosis, promoter, gastric cancer
DNA-binding domain, known as the forkhead box or winged helix domain (1). Recent studies indicate that FoxM1, activated by the Ras-MAPK and hedgehog signaling pathways $(2,3)$, plays an important role in the cell cycle by regulating genes essential for DNA synthesis, faithful chromosome regulation and mitosis $(4,5)$. FoxM1 maintains a dynamic balance between proliferation and apoptosis, and its dysfunction may alter the normal process of cell differentiation, eventually leading to carcinogenesis. Previous studies have demonstrated that FoxM1 is overexpressed in gastric cancer and that elevated FoxM1 levels promote tumor progression in glioma cells, breast cancer and lung adenocarcinomas, which correlates closely with a poor outcome (6-9). Moreover, FoxM1 amplification confers to acquired cisplatin resistance in breast cancer and primary resistance to gefitinib in non-small cell lung cancer (NSCLC) $(10,11)$, which suggests that the inhibition of FoxM1 expression may be a novel therapeutic strategy for gastric cancer. However, in order to acquire a complete understanding of the mechanisms through which FoxM1 is regulated, further investigation is required.

Human epidermal growth factor receptor-2 (Her-2) is a member of the epidermal growth factor receptor (EGFR) family of receptor tyrosine kinases (RTKs), involved in the development and progression of various solid tumor types, such as gastric cancer, pulmonary adenocarcinoma, colorectal and breast cancer $(6,12-14)$. Her-2 does not bind ligands directly, but can be transactivated by the other EGFRs, leading to an amplification of signal transduction (15). Emerging evidence suggests that EGFR family members, enhanced by ERK1/2 MAP kinase and phosphatidylinositol 3-kinase (PI3K)/protein kinase B (PKB also known as Akt) signaling cascades, are established regulators of cell proliferation and survival, and its aberrant signaling is a common feature of many tumor types (15-17). Moreover, the amplification of Her-2 in primary gastric cancer correlates with a poor prognosis and disease progression (18), whilst the Her-2 blocking antibody, trastuzumab (also known as Herceptin), is currently approved for the treatment of Her-2-positive breast cancer (19) and metastatic gastric cancer as a result of the ToGA trial (20). Given the overlapping roles of FoxM1 and Her-2 in cell proliferation, survival and gastric cancer development, as well as their role as therapeutic targets, it can be hypothesized that Her-2 may in part regulate FoxM1 expression in the development of gastric cancer and thereby promote cell cycle progression. In the present study, we aimed to examine this hypothesis by inves- 
tigating the association between FoxM1 and Her-2 expression in gastric cancer.

\section{Materials and methods}

Human tissue specimens and patient population. Gastric cancer tissues were obtained from 103 patients who underwent gastrectomy and D2 lymphadenectomy at the Affiliated Hospital of Qingdao University Medical College (Qingdao, China) from January 2007 to November 2007. A total of 68 adjacent cancer tissues, which were $>5 \mathrm{~cm}$ away from the edge of the tumor, were randomly selected. All patients met the following criteria: i) tumors were confirmed to be gastric adenocarcinoma histologically; ii) no patient had received preoperative treatment, such as chemotherapy or radiotherapy. The group of patients consisted of 35 females and 68 males with ages ranging between 33 and 80 years (mean age, 64 years). Clinico-pathological data were obtained from the operative and pathological examination of the patients, and are presented in Table III.

Cell lines and culture conditions. Five gastric cancer cell lines, SGC-7901, AGS, SNU16, MKN-28 and NCI-N87 and 2 normal gastric epithelial cell lines, GES-1 and HFE-145, which have different expression levels of FoxM1 and Her-2, were obtained from the Central Laboratory of the Affiliated Hospital of Qingdao University Medical College. All 7 cell lines were cultured in RPMI-1640, supplemented with $10 \%$ FBS (Thermo Scientific, San Jose, CA, USA) and 1\% penicillin/streptomycin, and incubated in $5 \% \mathrm{CO}_{2}$ at $37^{\circ} \mathrm{C}$. The anti-Her-2 tyrosine kinase inhibitor, trastuzumab (Chembest Research Laboratories, Shanghai, China), was dissolved in sterile water and diluted to a final concentration of 3,5 and $10 \mu \mathrm{g} / \mathrm{ml}$ prior to use, as previously described (21).

Immunohistochemistry (IHC). The expression of FoxM1 was detected by IHC with $3-\mu$ m-thick sections of formalin-fixed and paraffin-embedded blocks. For IHC staining, the tissue sections were dewaxed in xylene and rehydrated gradually with a graded series of ethanol. For antigen retrieval, all the sections were incubated in a microwave oven in citrate buffer solution (pH 6.0) for $20 \mathrm{~min}$. Endogenous peroxidase was inactivated by $0.3 \%$ hydrogen peroxide in methanol for $15 \mathrm{~min}$. Subsequently, the tissue slides were incubated with rabbit polyclonal antibody against human FoxM1 (dilution 1:100; Epitomics, Burlingame, CA, USA) and Her-2 (dilution 1:200; Abcam, Cambridge, MA, USA) at $4^{\circ} \mathrm{C}$ overnight and then the antibody binding sites were visualized with the SP peroxidase detection system. Finally, the sections were incubated in 3,3'-diaminobenzidine tetrahydrochloride for 3-10 min and restained with $0.1 \%$ hematoxylin. In each case, the negative control reaction was set with phosphate-buffered saline (PBS), replacing the antibody, while the known positively stained section was used as the positive control. The results of IHC were evaluated by 2 pathologists independently with no knowledge of the clinicopathological characteristics according to the semiquantitative immunoreactivity score (IRS) system suggested by in the study by Remmele and Stegner (22) and the Her-2 test criteria modified in the study by Hofmann et al (23).
Western blot analysis. Whole-cell lysates were prepared from human gastric cell lines which were in the logarithmic growth phase, $48 \mathrm{~h}$ after transfection or $72 \mathrm{~h}$ following incubation with trastuzumab. The protein concentration was determined using the Beijing Kaiao assay system (Beijing Kaiao Technology Development Co., Ltd., Beijing, China). Total protein was fractionated using sodium dodecyl sulfate polyacrylamide gel electrophoresis and transferred onto polyvinylidene fluoride membranes. Anti-FoxM1 (dilution 1:1,000; Epitomics), antiHer-2 (dilution 1:2,000; Abcam) and anti-GAPDH (dilution 1:2,000; CWBIO, Beijing, China) rabbit polyclonal antibodies were used as the primary antibodies. The signals were detected using the Vilber enhanced chemiluminescence system (Vilber Lourmat, Marne La Vallée, France) according to the manufacturer's instructions.

$R N A$ extraction and RT-PCR. Total cellular RNA was extracted from the cell pellets of each cell line using TRIzol reagent, according to the protocol suggested in the study by Okada et al (6). In addition, 70 gastric cancer tissues randomly selected from the 103 patients were used for RNA extraction. For these paraffin-embedded tissues, sufficient sections were prepared, deparaffinized and conventionally re-hydrated in a decreasing alcohol series prior to RNA extraction, as previously described (24). The amount of RNA was determined using the Beijing Kaiao assay system (K5500; Beijing Kaiao Technology Development Co., Ltd.), and then part of the RNA was reverse transcribed using the Reverse Transcription System (Takara Bio, Inc., Dalian, China). Samples were stored at $-80^{\circ} \mathrm{C}$ until use.

The primer sequences for PCR amplification were as follows: FoxM1 sense, 5'-TAT TCA CAG CAT CAT CAC AGC A-3' and antisense, 5'-GAA GGC TCC TCA ACC TTA ACC T-3'; Her-2 sense, 5'-TCT GCT GGA GGA ATT GGT GT-3' and antisense, 5'-GAC GCT TGT TCC CAC CTT GA-3'; GAPDH sense, 5'-ACC ACA GTC CTG CAT GCC AC-3' and antisense, 5'-TCC ACC ACC CTG TTG CTG TA-3'. To ensure experimental accuracy, all reactions were performed in triplicate. The integrity of all the RNA samples was verified by RT-PCR for GAPDH in each sample using a gel imaging system (Vilber Lourmat). The value of FoxM1 expression was divided by that of GAPDH in each sample.

Plasmids and transfection. The human Her-2 expression vector, pcDNA3.1-Her-2, Her-2-siRNA and the human FoxM1 promoter reporter plasmid were obtained from the Central Laboratory of the Affiliated Hospital of Qingdao University Medical College. For transfection, the cells were seeded to a 40-50\% confluent state and transfected with pcDNA3.1-Her-2, pcDNA3.1, Her-2-siRNA or non-specific siRNA using Lipofectamine 2000 (Invitrogen, Carlsbad, CA, USA) in accordance with the manufacturer's instructions. For the human FoxM1 promoter plasmids containing firefly luciferase reporters, an internal control, pMiniTK-RL, which included a full-length Renilla luciferase gene under the control of a minimal thymidine kinase promoter, was co-transfected into the gastric cancer cell lines in triplicate. Twenty-four hours after transfection, the cells were harvested for luciferase assay.

Luciferase reporter assay. For promoter analysis, $24 \mathrm{~h}$ after transfection, the cells were collected, washed twice in PBS, 
A

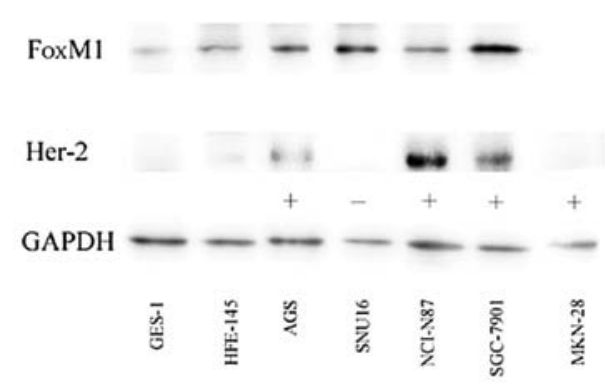

$\mathrm{B}$
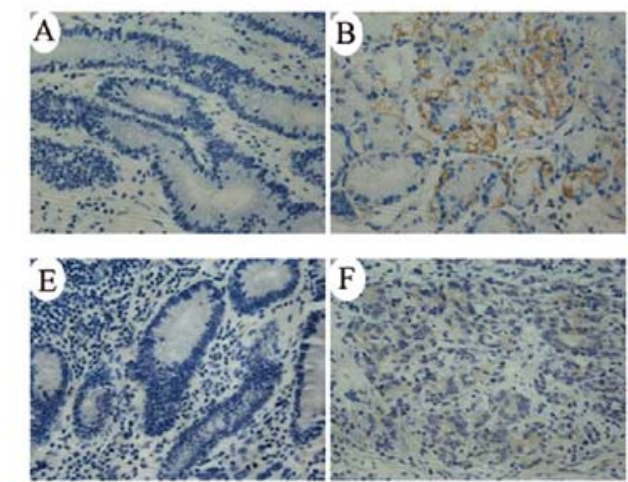
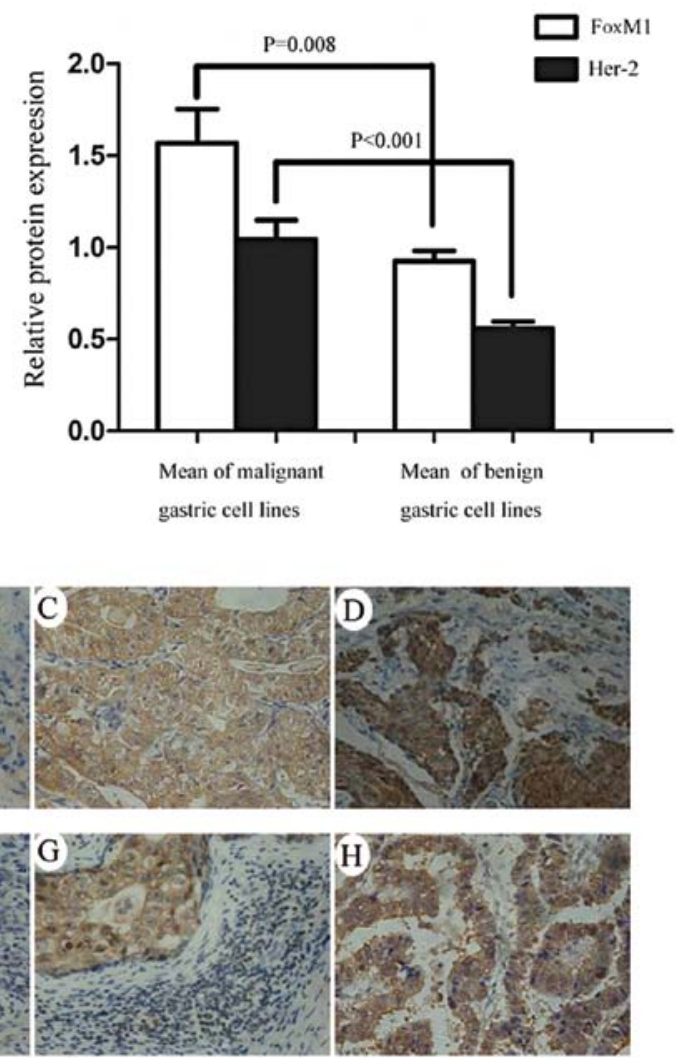

Figure 1. Expression of forkhead box protein M1 (FoxM1) and human epidermal growth factor receptor-2 (Her-2) in gastric cell lines and tissues. (A) Differential expression of FoxM1 and Her-2 in benign and malignant human gastric cell lines. Left panel: expression of FoxM1 and Her-2 in 2 normal gastric cell lines (GES-1 and HFE-145) and 5 gastric cancer cell lines (SGC-7901, AGS, SNU16, MKN-28 and NCI-N87). Her-2 expression correlated with FoxM1 protein expression in gastric cancer cell lines, as shown by western blot analysis. +, positive correlation; -, no correlation for each cell line. Right panel: significant difference in the expression of FoxM1 $(\mathrm{P}=0.008)$ and Her-2 $(\mathrm{P}<0.001)$ between benign and malignant human gastric cell line groups, analyzed by a t-test. (B) Immunohistochemical staining for FoxM1 and Her-2 antibody in human gastric cancer tissues and adjacewnt cancer tissues (magnification, $\mathrm{x} 400$ ). The paraffin-embedded gastric tissues were stained with antibodies to (A-D) FoxM1 and (E-H) Her-2. FoxM1 was mainly expressed in the nuclei or cytoplasm of the cells, while Her-2 expression was mainly observed in the membrane or cytoplasm. Of the 103 gastric cancer samples, 15 were negative for both FoxM1 and Her-2, 7 were Her-2-positive only, and 73 were FoxM1-positive only.

and harvested for firefly/Renilla luciferase assays using the Dual-Glo $^{\text {TM }}$ Luciferase reporter assay system (Promega, Madison, WI, USA) according to the manufacturer's instructions. Subsquently, luminescence was read using the Tecan Safire II microplate reader (Tecan, Männedorf, Switzerland).

Statistical analysis. The SPSS 19.0 software package (SPSS Inc., Chicago, IL, USA) was used for the statistical analysis. The $\chi^{2}$ test and the Student's t-test were performed to determine the difference between the different subgroups. A value of $\mathrm{P}<0.05$ was considered to indicate a statistically significant difference.

\section{Results}

Overexpression of FoxM1 and Her-2 expression in both malignant human gastric cell lines and gastric cancer tissues. We initiated our study by investigating the expression level of FoxM1 and Her-2 in benign and malignant human gastric cell lines. Western blot analysis revealed a homogenous FoxM1 expression in the normal gastric epithelial cell lines (GES-1 and HFE-145), whereas the expression levels were more heterogeneous and elevated in the cancerous cell lines (Fig. 1A) $(\mathrm{P}=0.008)$. In the malignant human gastric cell lines, only the
SGC-7901, NCI-N87 and AGS cells exhibited the expression of Her-2, whereas low expression levels were observed in the non-malignant gastric cell lines, among which, the differences were significant (Fig. 1A) $(\mathrm{P}<0.001)$.

In the gastric cancer tissues, FoxM1 was stained positive in the nuclei or cytoplasm of $79 \%$ of the cells, while this number was $14 \%$ for Her-2 (Fig. 1B). However, much lower levels of FoxM1 and Her-2 expression were observed in the adjacent cancer tissues (11.8 and 1.5\%), which demonstrated that the level of FoxM1 and Her-2 expression was significantly higher in the gastric cancer than in the adjacent cancer tissues (Table I) $(\mathrm{P}<0.001$ and $\mathrm{P}=0.004)$, indicating that FoxM1 is overexpressed in human gastric cancer.

Her-2 expression correlates with FoxM1 expression at the protein and $m R N A$ level. To examine whether FoxM1 expression correlates with Her-2 expression, we analyzed Her-2 and FoxM1 expression in a panel of 5 different malignant gastric cell lines by western blot analysis. Consistent with our hypothesis that Her-2 may partly regulate FoxM1 expression, 3 gastric cancer cell lines positive for Her-2 expression exhibited high levels of FoxM1 protein, whilst one cell line with no Her-2 expression also lacked the expression of FoxM1 (Fig. 1A). Therefore, 4 of the 5 gastric cancer cell lines demonstrated a 
Table I. Differential FoxM1 and Her-2 expression in human gastric cancer tissues and adjacent cancer tissues.

\begin{tabular}{|c|c|c|c|c|}
\hline \multirow[b]{2}{*}{ Variable } & \multicolumn{2}{|c|}{ FoxM1 } & \multicolumn{2}{|c|}{ Her-2 } \\
\hline & Positive & Negative & Positive & Negative \\
\hline Gastric cancer tissues & 81 & 22 & 15 & 88 \\
\hline Paraneoplastic tissues & 8 & 60 & 1 & 67 \\
\hline$\chi^{2}$ & & 81.075 & & 8.278 \\
\hline P-value & & $<0.001$ & & 0.004 \\
\hline
\end{tabular}

FoxM1, forkhead box protein M1; Her-2, human epidermal growth factor receptor-2.

Table II. Significant association between the expression of FoxM1 and Her-2 in human gastric cancer tissues ( $\mathrm{P}=0.025)$.

\begin{tabular}{lcccr}
\hline Variable & Her-2-negative & Her-2-positive & $\chi^{2}$ & P-value \\
\hline FoxM1-negative & 15 & 7 & 5.047 & 0.025 \\
FoxM1-positive & 73 & 8 & & \\
\hline
\end{tabular}

FoxM1, forkhead box protein M1; Her-2, human epidermal growth factor receptor-2.

positive correlation between the levels of Her-2 and FoxM1. One of the cell lines did not exhibit this correlation; in this case, it is possible that other mechanisms may influence the FoxM1 levels more significantly. Moreover, at the transcription level, similar results were obtained by RT-PCR, in which the positive correlation was observed in most of the malignant gastric cell lines (Fig. 2A).

To confirm that the correlation between FoxM1 and Her-2 expression is also valid in tumor tissues, a series of 103 paraffinembedded gastric cancer samples were immunohistochemically stained for Her-2 and FoxM1. As expected, in the gastric cancer samples, the majority of cells with Her-2 expression were positively stained for FoxM1, whilst the samples devoid of Her-2 staining also lacked FoxM1 expression (Fig. 1B). Statistical analysis revealed that there was a significant and positive correlation between FoxM1 and Her-2 expression $(\mathrm{P}=0.025)$ (Table II). Nevertheless, no significant association was observed between the expression of FoxM1 and any clinicopathological characteristics (Table III; P>0.1), whereas the frequency of Her-2-positive cases significantly correlated with the TNM stage $(\mathrm{P}=0.045)$. To investigate whether Her-2 overexpression is associated with increased levels of FoxM1 expression at the transcriptional level, we examined FoxM1 mRNA levels by RT-PCR in 70 randomly selected gastric cancer tissues. Consistent with our previous data, the RT-PCR results indicated that when the patient samples were categorized by their Her-2 status, the Her-2-positive samples had a significantly higher expression of FoxM1 at the transcriptional level (Fig. 2B; $\mathrm{P}=0.007$ ).

Alterations in Her-2 expression modulate FoxM1 expression in gastric cancer cell lines. To determine whether Her-2 regulates FoxM1 expression, different levels of pcDNA3.1-Her-2 or the empty vector were transfected into the SGC-7901, AGS and
SNU16 cells. Our results revealed that the FoxM1 expression level was increased following transfection with Her-2 expression vectors, of which the amplification coincided with the levels of Her-2 expression, as shown by western blot analysis (Fig. 3A).

To further validate that Her-2 partly regulates FoxM1, we transfected the SGC-7901 and NCI-N87 cells with Her-2siRNA or non-specific siRNA. The ablation of Her-2 in the cells resulted in a reduced FoxM1 expression at the protein level (Fig. 3B, top panel). Moreover, when the gastric cell lines, SGC-7901 and NCI-N87, were treated with various concentrations $(0,5$ or $10 \mu \mathrm{g} / \mathrm{ml})$ of anti-trastuzumab (an Her-2 tyrosine kinase inhibitor), similar results were observed, and as the concentration of trastuzumab increased, the expression of FoxM1 was downregulated (Fig. 3B, bottom panel).

Her-2 regulates FoxM1 expression at the promoter level. To investigate whether FoxM1 is a downstream signaling target of Her-2 in gastric cancer, we co-transfected the FoxM1 promoter reporter plasmid with Her-2 overexpression vectors or Her-2-siRNA into the human malignant gastric cell lines. The results of luciferase reporter assays (Fig. 4) revealed that the relative luciferase activity was generally elevated with the increasing pcDNA3.1-Her-2 concentration in the AGS and SGC-7901 cells (Fig. 4A), while Her-2-siRNA inhibited the luciferase activity driven by the FoxM1 promoter in the NCI-N87 and SGC-7901 cells (Fig. 4B), verifying that Her-2 regulates FoxM1 expression at the transcriptional level.

In order to further confirm this result, we then transfected FoxM1 promoter reporter plasmids and trastuzumab into the SGC-7901 and NCI-N87 cells. Twenty-four hours later, the luciferase activity of the promoter reporter construct was observed to be decreased (Fig. 4C), which indicated that trastuzumab induced a reduction in FoxM1 expression and further supports our hypothesis. 
A

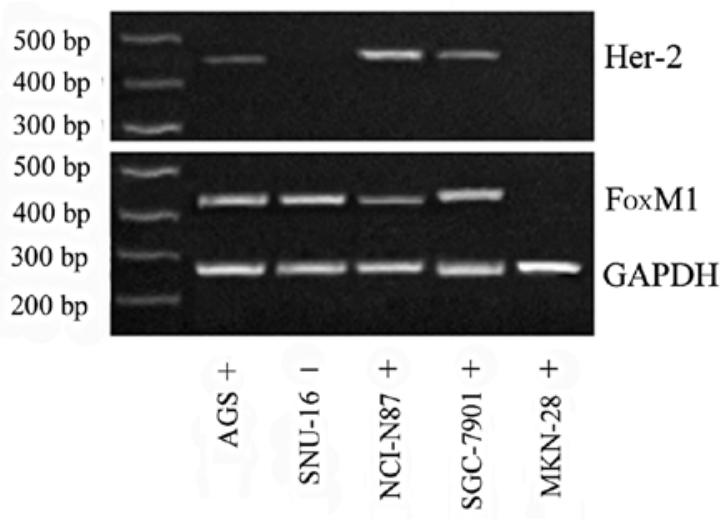

$\mathrm{B}$

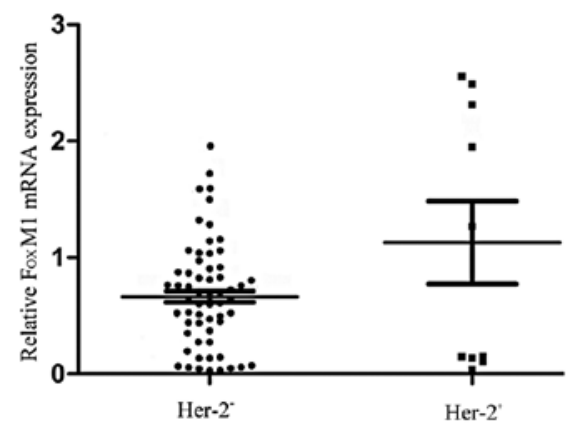

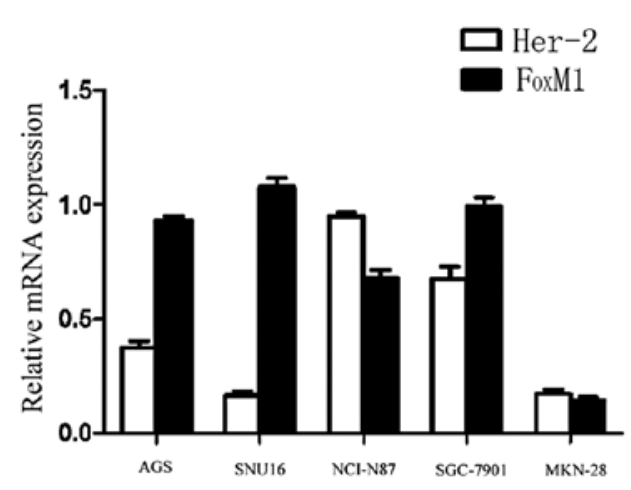

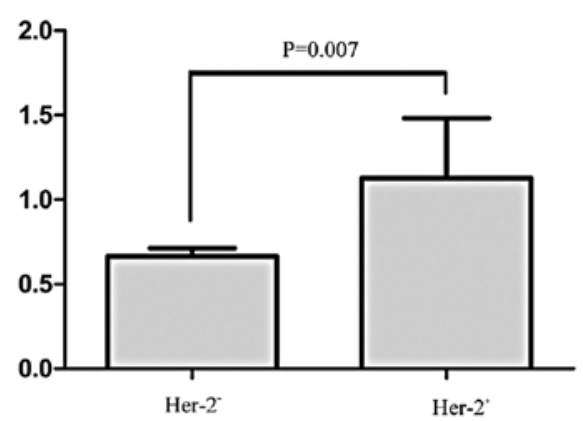

Figure 2. The mRNA levels of forkhead box protein M1 (FoxM1) and human epidermal growth factor receptor-2 (Her-2) in gastric cancer cell lines and tissues. (A) Different levels of FoxM1 and Her-2 mRNA in malignant gastric cell lines. Left panel: Her-2 correlated with FoxM1 in gastric cancer cell lines, as shown by RT-PCR. +, positive correlation; -, no correlation for each cell line. Right panel: relative mRNA expression of FoxM1 and Her-2 exhibited by a histogram. (B) mRNA level of FoxM1 correlated with Her-2 expression in human gastric cancer tissues. RNA was obtained from 70 paraffin-embedded gastric cancer samples which were randomly selected. The graph on the left shows the relative FoxM1 mRNA expression of each sample after being divided into Her-2-positive or -negative groups. The graph on the right exhibits the mean \pm standard deviation of the 2 groups, between which the difference was significant, as shown by the Student's t-test $(\mathrm{P}=0.007)$.

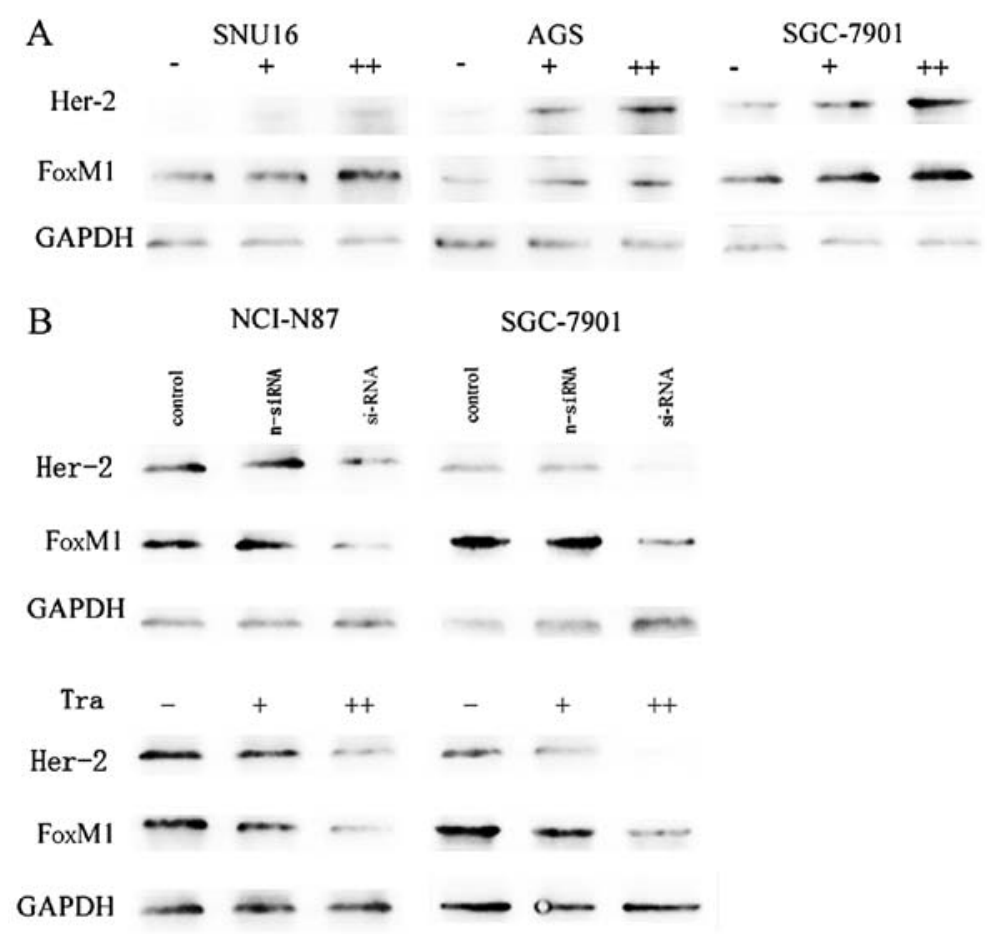

Figure 3. The regulation of forkhead box protein M1 (FoxM1) expression by different levels of human epidermal growth factor receptor-2 (Her-2) in human gastric cell lines. (A) Expression of FoxM1 following transfection of the gastric cell lines, SNU16, AGS and SGC-7901, with the empty vector or 3 or 5 mg of pcDNA3.1-Her-2, analyzed by western blot analysis $48 \mathrm{~h}$ later. (B) Top panel: the expression of FoxM1 following transfection of the NCI-N87 and SGC-7901 cells with transfection reagent, $50 \mathrm{nM}$ non-specific siRNA or $50 \mathrm{nM}$ Her-2-siRNA for $48 \mathrm{~h}$. Bottom panel: the expression of FoxM1 following treatment of the gastric cell lines, NCI-N87 and SGC-7901, with 0,5 or $10 \mu \mathrm{g} / \mathrm{ml}$ trastuzumab for $72 \mathrm{~h}$. The protein lysate were then detected by western blot analysis. 
Table III. Association between FoxM1 or Her-2 and clinicopathological characteristics in 103 patients following gastrectomy.

\begin{tabular}{|c|c|c|c|c|c|c|}
\hline & \multicolumn{3}{|c|}{ FoxM1 } & \multicolumn{3}{|c|}{ Her-2 } \\
\hline & Negative & Positive & P-value & Negative & Positive & P-value \\
\hline \multicolumn{7}{|l|}{ Age (years) } \\
\hline$\leq 50$ & 4 & 13 & 1 & 15 & 4 & 0.598 \\
\hline$>50$ & 18 & 68 & & 73 & 11 & \\
\hline \multicolumn{7}{|l|}{ Gender } \\
\hline Male & 15 & 53 & 0.809 & 59 & 9 & 0.591 \\
\hline Female & 7 & 28 & & 29 & 6 & \\
\hline \multicolumn{7}{|l|}{ Size $(\mathrm{cm})$} \\
\hline$\leq 5$ & 15 & 58 & 0.754 & 61 & 12 & 0.593 \\
\hline$>5$ & 7 & 23 & & 27 & 3 & \\
\hline \multicolumn{7}{|c|}{ Depth of tumor invasion } \\
\hline $\mathrm{T} 1-2$ & 7 & 33 & 0.446 & 37 & 3 & 0.105 \\
\hline $\mathrm{T} 3-4$ & 15 & 48 & & 51 & 12 & \\
\hline \multicolumn{7}{|c|}{ Lymph node metastatis } \\
\hline Negative & 8 & 32 & 0.789 & 36 & 4 & 0.295 \\
\hline Positive & 14 & 49 & & 52 & 11 & \\
\hline \multicolumn{7}{|c|}{ Degree of differentiation } \\
\hline Undifferentiated & 17 & 58 & 0.596 & 66 & 9 & 0.372 \\
\hline Differentiated & 5 & 23 & & 22 & 6 & \\
\hline \multicolumn{7}{|l|}{ Venous invasion } \\
\hline Negative & 14 & 47 & 0.701 & 54 & 7 & 0.284 \\
\hline Positive & 8 & 34 & & 34 & 8 & \\
\hline \multicolumn{7}{|l|}{ Neural invasion } \\
\hline Negative & 10 & 46 & 0.344 & 47 & 9 & 0.636 \\
\hline Positive & 12 & 35 & & 41 & 6 & \\
\hline \multicolumn{7}{|l|}{ TNM staging } \\
\hline I-II & 7 & 38 & 0.206 & 42 & 3 & $0.045^{\mathrm{a}}$ \\
\hline III-IV & 15 & 43 & & 46 & 12 & \\
\hline
\end{tabular}

${ }^{\mathrm{a}} \mathrm{P}<0.05$. FoxM1, forkhead box protein M1; Her-2, human epidermal growth factor receptor-2.

\section{Discussion}

In the present study, we demonstrate that FoxM1 and Her-2 expression is significantly higher in gastric cancer than in adjacent cancer tissues and gastric cell lines. A strong association was observed between Her-2 and FoxM1 expression at the mRNA and protein level. When we regulated the level of Her-2 in the gastric cancer cell lines, the expression of FoxM1 changed accordingly, indicating that the expression level of FoxM1 was at least partially regulated by Her-2. In order to validate our results, we transfected FoxM1 promoter reporter plasmids and Her-2 expression vectors into malignant human gastric cell lines, where the luciferase activity of the promoter reporter construct increased with the increasing amount of pcDNA3.1-Her-2. Consistently, when Her-2-positive cells were incubated with Her-2-siRNA or the Her-2 inhibitor, trastuzumab, the transfected FoxM1 promoter reporter constructs showed a decrease in promoter activity. Our results demonstrate that FoxM1 and Her-2 are important diagnostic markers for gastric cancer, and that the upregulation of FoxM1 expression is at least partially mediated at the mRNA level through the regulation of the FoxM1 promoter by Her-2.

The Her- 2 gene is localized on chromosome $17 \mathrm{q}$ and codes for a transmembrane glycoprotein of $185 \mathrm{kDa}$. Her-2 plays an important role in normal development, differentiation and apoptosis of cells. Her-2 gene amplification has been reported in various types of cancer, including ovarian, lung and breast cancers $(13,14,25)$. It has been reported that Her-2 is overexpressed in $9-38 \%$ of patients with gastric cancer (26), and is associated with certain clinicopathological characteristics and a poor survival in univariate analysis, but is not independently correlated with prognosis in multivariate analysis $(27,28)$. However, in the studies by Okada et al (6) and Li et al (29), positive FoxM1 expression was an independent prognostic factor in gastric cancer, but did not correlate with any clinicopathological characteristics; the opposite occurred for Her-2. 


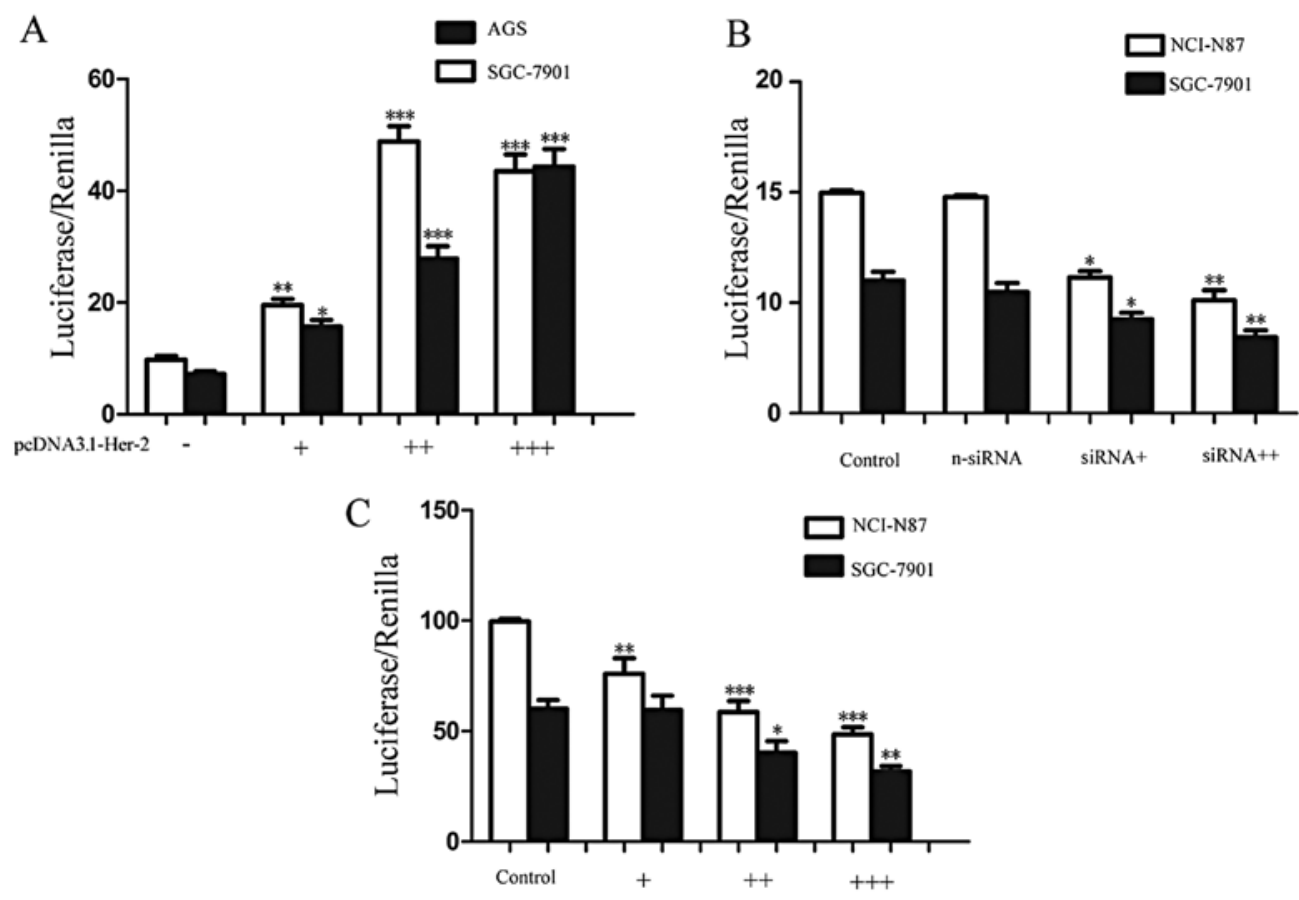

Figure 4. The luciferase activity of forkhead box protein M1 (FoxM1) promoter reporter vectors modulated by human epidermal growth factor receptor-2 (Her-2) levels in human gastric cell lines. (A) AGS and SGC-7901 cells were transfected with FoxM1 promoter reporter vectors and increasing amounts (0.2, 0.4 and $0.6 \mathrm{ng}$ ) of pcDNA3.1-Her-2. (B) NCI-N87 and SGC-7901 cells were co-transfected with FoxM1 promoter reporter vectors and transfection reagent, non-specific siRNA (n-siRNA) or different amounts [10 nM (siRNA+) and $20 \mathrm{nM}$ (siRNA++)] of Her-2-siRNA. (C) NCI-N87 and SGC-7901 cells transfected with FoxM1 promoter reporter vectors were then treated with $0,3,5$ or $10 \mu \mathrm{g} / \mathrm{ml}$ trastuzumab. Twenty-four hours later, the cells were collected for luciferase assays. The relative luciferase activity values were corrected for co-transfected Renilla activity. The data are presented as means \pm standard deviation. ${ }^{*} \mathrm{P} \leq 0.05$, ${ }^{* *} \mathrm{P} \leq 0.01,{ }^{* * *} \mathrm{P} \leq 0.001$ indicate statistically significant differences.

The results from the present study are in agreement with those of previous studies, as no significant association was found between the expression of FoxM1 and any clinicopathological characteristics, while Her-2 expression only significantly correlated with the TNM stage. Additionally, in agreement with the study by Okada et al (6), our study revealed that FoxM1 was associated with a poor survival, consistent with Her-2. Therefore, these results indicate that these two genes have a similar tendency as regards clinicopathological parameters and survival, suggesting that Her-2 expression may correlate with FoxM1 expression significantly.

Our present data revealed that FoxM1 is associated with Her-2 expression in gastric cancer, and that it is a downstream cellular target of Her-2-dependent signaling, which activates FoxM1 expression at the protein, mRNA and gene promoter levels. It has been reported that FoxM1 overexpression confers resistance to the Her-2 monoclonal antibody, trastuzumab (21); the mechanisms through which Her-2 regulates FoxM1 expression levels may be critical for understanding the mechanisms of FoxM1-mediated acquired resistance to Her-2. Moreover, previous studies have shown that Her- 2 and its co-receptor, EGFR, suppress FOXO3a through the PI3K-Akt pathway, while FOXO3a inactivation releases a switch in promoter occupancy from FoxM1, which then modulates the cell cycle through the Cdc25B, CDK1, cyclin B and p27KIP genes $(4,5,30,31)$. The PI3K-Akt-FOXO3a signaling axis may provide the link between Her-2 and FoxM1 expression. Of note, FOXO has been revealed to have opposite effects with FoxM1 on the reaction to a diverse spectrum of anticancer drugs, such as lapatinib and gefitinib (32), and thus it can be concluded that FOXO may be discussed as a novel anticancer agent of Her-2-overexpressing cancers in further investigations.

The ToGA trial (20) led to the conclusion that trastuzumab can be used to treat patients with Her-2 overexpression, and thus the determination of the Her-2 status is a very important step in clinical routine to determine the therapeutic strategy. However, the majority of patients develop resistance to trastuzumab during therapy (33), indicating that the analyses of other potential target molecules in signaling pathways of malignant gastric cells are of great interest and may offer alternative treatment options for patients with resistance to trastuzumab. FoxM1 may be such a candidate molecule. FoxM1 inhibitors have been discussed as novel anticancer therapeutics (34-36), which may prove to be a successful tool to sensitize various tumor types to treatment. Bhat et al (34) suggested that Siomycin A and thiostrepton (FoxM1 inhibitors/thiazole antibiotics) may be potentially developed as novel anticancer drugs against human neoplasia (35). Furthermore, Gusarova et al (35) showed that the inhibition of FoxM1 function by a cell-penetrating ARF peptide led to reduced tumor cell proliferation and angiogenesis in hepatocellular carcinoma (36). Nevertheless, this inhibitory effect on FoxM1 has not been analyzed for human gastric cancer thus far. Therefore, further functional studies are required to focus on the function of FoxM1 in Her-2-targeted therapy-resistant gastric cancer.

Although this study provides evidence of the regulation of Her- 2 on the FoxM1 gene promoter, accurate binding sites at the gene level were not revealed yet. Moreover, from the differential expression of FoxM1 and Her-2 in gastric cancer tissues and cell lines, we can infer that there are other mechanisms 
that may also influence the expression of FoxM1; this requires further investigation.

In conclusion, our results suggest that FoxM1 and Her-2 are important diagnostic markers for gastric cancer. FoxM1 could be a potential cellular target for therapeutic intervention, particularly in Her2-targeted therapy-resistant cancers.

\section{Acknowledgements}

This study was supported by a grant from the Medicine and Healthy Technology Development Program of Shandong province (2011HZ028).

\section{References}

1. Wierstra I and Alves J: FOXM1, a typical proliferation-associated transcription factor. Biol Chem 388: 1257-1274, 2007.

2. Ma RY, Tong TH, Leung WY and Yao KM: Raf/MEK/MAPK signaling stimulates the nuclear translocation and transactivating activity of FOXM1. Methods Mol Biol 647: 113-123, 2010.

3. Katoh Y and Katoh M: Hedgehog target genes: mechanisms of carcinogenesis induced by aberrant hedgehog signaling activation. Curr Mol Med 9: 873-886, 2009.

4. Wang IC, Chen YJ, Hughes D, Petrovic V, Major ML, Park HJ, Tan Y, Ackerson T and Costa RH: Forkhead box M1 regulates the transcriptional network of genes essential for mitotic progression and genes encoding the SCF (Skp2-Cks1) ubiquitin ligase. Mol Cell Biol 25: 10875-10894, 2005.

5. Costa RH: FoxM1 dances with mitosis. Nat Cell Biol 7: 108-110, 2005 .

6. Okada K, Fujiwara Y, Takahashi T, Nakamura Y, Takiguchi S, Nakajima K, Miyata H, Yamasaki M, Kurokawa Y, Mori M and Doki Y: Overexpression of forkhead box M1 transcription factor (FOXM1) is a potential prognostic marker and enhances chemoresistance for docetaxel in gastric cancer. Ann Surg Oncol 20: 1035-1043, 2013.

7. Liu M, Dai B, Kang SH, Ban K, Huang FJ, Lang FF, Aldape KD, Xie TX, Pelloski CE, Xie K, Sawaya R and Huang S: FoxM1B is overexpressed in human glioblastomas and critically regulates the tumorigenicity of glioma cells. Cancer Res 66: 3593-3602, 2006.

8. Yau C, Wang Y, Zhang Y, Foekens JA and Benz CC: Young age, increased tumor proliferation and FOXM1 expression predict early metastatic relapse only for endocrine-dependent breast cancers. Breast Cancer Res Treat 126: 803-810, 2011.

9. Kim IM, Ackerson T, Ramakrishna S, Tretiakova M, Wang IC, Kalin TV, Major ML, Gusarova GA, Yoder HM, Costa RH and Kalinichenko VV: The Forkhead Box $\mathrm{m} 1$ transcription factor stimulates the proliferation of tumor cells during development of lung cancer. Cancer Res 66: 2153-2161, 2006.

10. Xu N, Zhang X, Wang X, Ge HY, Wang XY, Garfield D, Yang P, Song YL and Bai CX: FoxM1 mediated resistance to gefitinib in non-small-cell lung cancer cells. Acta Pharmacol Sin 33: 675-681, 2012.

11. Kwok JM, Peck B, Monteiro LJ, Schwenen HD, Millour J, Coombes RC, Myatt SS and Lam EW: FOXM1 confers acquired cisplatin resistance in breast cancer cells. Mol Cancer Res 8: 24-34, 2010

12. Koeppen HK, Wright BD, Burt AD, Quirke P, McNicol AM, Dybdal NO, Sliwkowski MX and Hillan KJ: Overexpression of HER2/neu in solid tumours: an immunohistochemical survey. Histopathology 38: 96-104, 2001.

13. Kaptain S, Tan LK and Chen B: Her-2/neu and breast cancer. Diagn Mol Pathol 10: 139-152, 2001.

14. Hirashima N, Takahashi W, Yoshii S, Yamane T and Ooi A: Protein overexpression and gene amplification of c-erb B-2 in pulmonary carcinomas: a comparative immunohistochemical and fluorescence in situ hybridization study. Mod Pathol 14: 556-562, 2001.

15. Zhang H, Berezov A, Wang Q, Zhang G, Drebin J, Murali R and Greene MI: ErbB receptors: from oncogenes to targeted cancer therapies. J Clin Invest 117: 2051-2058, 2007.

16. Yarden Y and Sliwkowski MX: Untangling the ErbB signalling network. Nat Rev Mol Cell Biol 2: 127-137, 2001.
17. Montemurro F, Valabrega $\mathrm{G}$ and Aglietta M: Lapatinib: a dual inhibitor of EGFR and HER2 tyrosine kinase activity. Expert Opin Biol Ther 7: 257-268, 2007.

18. Garcia I, Vizoso F, Martin A, Sanz L, Abdel-Lah O, Raigoso P and Garcia-Muniz JL: Clinical significance of the epidermal growth factor receptor and HER2 receptor in resectable gastric cancer. Ann Surg Oncol 10: 234-241, 2003.

19. Tripathy D, Slamon DJ, Cobleigh M, Arnold A, Saleh M, Mortimer JE, Murphy M and Stewart SJ: Safety of treatment of metastatic breast cancer with trastuzumab beyond disease progression. J Clin Oncol 22: 1063-1070, 2004.

20. Bang YJ, Van Cutsem E, Feyereislova A, Chung HC, Shen L, Sawaki A, Lordick F, Ohtsu A, Omuro Y, Satoh T, Aprile G, Kulikov E, Hill J,Lehle M, Ruschoff J and Kang YK; ToGA Trial Investigators: Trastuzumab in combination with chemotherapy versus chemotherapy alone for treatment of HER2-positive advanced gastric or gastro-oesophageal junction cancer (ToGA): a phase 3, open-label, randomised controlled trial. Lancet 376: 687-697, 2010.

21. Carr JR, Park HJ, Wang Z, Kiefer MM and Raychaudhuri P: FoxM1 mediates resistance to herceptin and paclitaxel. Cancer Res 70: 5054-5063, 2010.

22. Remmele W and Stegner HE: Recommendation for uniform definition of an immunoreactive score (IRS) for immunohistochemical estrogen receptor detection (ER-ICA) in breast cancer tissue. Pathologe 8: 138-140, 1987 (In German).

23. Hofmann M, Stoss O, Shi D, Buttner R, van de Vijver M, Kim W, Ochiai A, Ruschoff J and Henkel T: Assessment of a HER2 scoring system for gastric cancer: results from a validation study. Histopathology 52: 797-805, 2008.

24. Huang WY, Sheehy TM, Moore LE, Hsing AW and Purdue MP: Simultaneous recovery of DNA and RNA from formalin-fixed paraffin-embedded tissue and application in epidemiologic studies. Cancer Epidemiol Biomarkers Prev 19: 973-977, 2010.

25. McKenzie SJ, DeSombre KA, Bast BS, Hollis DR, Whitaker RS, Berchuck A, Boyer CM and Bast RC Jr: Serum levels of HER-2 neu (C-erbB-2) correlate with overexpression of p185neu in human ovarian cancer. Cancer 71: 3942-3946, 1993.

26. Dang HZ, Yu Y and Jiao SC: Prognosis of HER2 overexpressing gastric cancer patients with liver metastasis. World J Gastroenterol 18: 2402-2407, 2012.

27. Zhou F, Li N, Jiang W, Hua Z, Xia L, Wei Q and Wang L: Prognosis significance of HER-2/neu overexpression/amplification in Chinese patients with curatively resected gastric cancer after the ToGA clinical trial. World J Surg Oncol 10: 274, 2012.

28. Halon A, Donizy P, Biecek P, Rudno-Rudzinska J, Kielan W and Matkowski R: HER-2 expression in immunohistochemistry has no prognostic significance in gastric cancer patients. ScientificWorldJournal 2012: 941259, 2012.

29. Li Q, Zhang N, Jia Z, Le X, Dai B, Wei D, Huang S, Tan D and Xie K: Critical role and regulation of transcription factor FoxM1 in human gastric cancer angiogenesis and progression. Cancer Res 69: 3501-3509, 2009.

30. Guo S and Sonenshein GE: Forkhead box transcription factor FOXO3a regulates estrogen receptor alpha expression and is repressed by the Her-2/neu/phosphatidylinositol 3-kinase/Akt signaling pathway. Mol Cell Biol 24: 8681-8690, 2004.

31. Delpuech O, Griffiths B, East P, Essafi A, Lam EW, Burgering B, Downward $\mathbf{J}$ and Schulze A: Induction of Mxil-SR alpha by FOXO3a contributes to repression of Myc-dependent gene expression. Mol Cell Biol 27: 4917-4930, 2007.

32. Wilson MS, Brosens JJ, Schwenen HD and Lam EW: FOXO and FOXM1 in cancer: the FOXO-FOXM1 axis shapes the outcome of cancer chemotherapy. Curr Drug Targets 12: 1256-1266, 2011.

33. Nahta R and Esteva FJ: HER2 therapy: molecular mechanisms of trastuzumab resistance. Breast Cancer Res 8: 215, 2006.

34. Bhat UG, Halasi M and Gartel AL: Thiazole antibiotics target FoxM1 and induce apoptosis in human cancer cells. PLoS One 4: e5592, 2009.

35. Gusarova GA, Wang IC, Major ML, Kalinichenko VV, Ackerson T, Petrovic V and Costa RH: A cell-penetrating ARF peptide inhibitor of FoxM1 in mouse hepatocellular carcinoma treatment. J Clin Invest 117: 99-111, 2007.

36. Radhakrishnan SK, Bhat UG, Hughes DE, Wang IC, Costa RH and Gartel AL: Identification of a chemical inhibitor of the oncogenic transcription factor forkhead box M1. Cancer Res 66: 9731-9735, 2006. 